\title{
Factors Affecting Immunization Status of Children Aged From 0-59 Months in Ethiopia
}

\author{
Gedif Mulat Alemayehu', Kasim Mohammed Yesuf ${ }^{2}$, Jibril Seid Yesuf ${ }^{3}$ \\ ${ }^{1}$ Department of Statistics, College of Natural \& Computational Sciences, Injibara University, P.O.Box 40, Injibara, Ethiopia, ${ }^{2}$ Department of Statistics, College of \\ Natural \& Computational Sciences, University of Gondar P.O. Box 196, Gondar, Ethiopia, ${ }^{3}$ Department of Pharmacology, School of Pharmacy, College of Medicine \\ and Health Sciences, University of Gondar, P.O. Box. 196, Gondar, Ethiopia.
}

\section{Abstract}

Background: Immunization is the process of stimulating the body's immunity against certain infectious diseases by administering vaccines. It is one of the main health interventions to prevent childhood morbidity and mortality. Objective: The objectives of the study were to determine the immunization coverage among children of aged 0-59 months old towards eight vaccine preventable diseases, to assess demographic and socio economic factors affecting immunization status among children aged 0-59 months and to assess the effect of media on immunization and vaccination status of children. Subjects and Methods: The data for this study were obtained from the Central Statistical Agency (CSA) on the 2011 Ethiopian Demographic and Health Survey (EDHS). The 2011 EDHS was the third national demographic and health survey conducted by CSA. The 2011 EDHS was conducted with the primary objective of generating health and demographic information on infant health and children vaccination, family planning, adult and maternal mortality, child and maternal nutrition, malaria, women's empowerment, and knowledge of HIV/AIDS along with other household characteristics in the nine regions and two administrative regions both at rural and urban levels. The nationally representative EDHS 2011 data was collected under the guidance of the Central Statistical Agency of Ethiopia. Interviews were conducted with 16515 women, 14110 men and 11654 children (0-59 months). The data was analyzed using the statistical package for social science (SPSS) version 20 and Stata version 11. Results: The highest rate (75.5\%) of children vaccinated was observed for mothers in the age group 45-49. On the other hand the lowest rate (59.8\%) of vaccinated children was observed from mothers in the age group 15-19. The result of study reviled that mothers' age in 5-year groups, place of residence, mothers' education level, region, religion, frequency of listening to radio, wealth index and birth order are the most important factors of child vaccination status in Ethiopia. Conclusion: Mothers who had higher education, aged 40-44, live in urban, live in Tigray, and listen radio at least once a week are more likely to vaccinate their children. Being the first child for parents is more likely to be vaccinated than being fifth and above order. The health offices should work properly to raise the awareness of parents for vaccination by designing proper health education.

Keywords: Immunization Status, Under Five Children, Risk Factor, Logistic Regression, Ethiopia.

Corresponding Author: Mr. Kasim Mohammed Yesuf, Department of Statistics, College of Natural \& Computational Sciences, University of Gondar P.O. Box 196, Gondar, Ethiopia.

Received: $2^{\text {nd }}$ January 2019

Accepted: $15^{\text {th }}$ February 2019

\section{Introduction}

Reducing child mortality and morbidity rates in SubSaharan Africa (SSA) has been the leading focus of the Millennium Development Goals (MDG). More than 50\% percent of child death in this area is because of lack of immunization coverage. Immunization is the process whereby a person is made immune or resistant to an infectious disease, typically by the administration of a vaccine. Vaccines stimulate the body's own immune system to protect the person against subsequent infection or disease. Immunization is a proven tool for controlling and eliminating life-threatening infectious diseases and is estimated to avert between 2 and 3 million deaths each year. It is one of the most cost-effective health investments, with proven strategies that make it accessible to even the most hard-to-reach and vulnerable populations. ${ }^{[1]}$
Immunized children are at lower risk of early child death, malnutrition, and poor health in adulthood. ${ }^{[2]}$ Immunization has an important role in medical innovations that contributed to declines in mortality following the improvements in sanitation, clean water and personal hygiene which are more directly associated with the demographic transition of the 19th and early 20th centuries. Today's vaccines protect children against diseases that once caused serious illness, even death, among those children who contracted them and have significantly improved the quality of life for many children and their families. It is for these reasons that childhood immunizations have been proclaimed one of the greatest public health success stories. ${ }^{[3]}$

Every year more than 2 million children die from diseases that could have been prevented by inexpensive vaccines. ${ }^{[4]}$ While many countries have increased immunization rates over time, coverage is still low in some countries. In 2003, 
average coverage for measles and diphtheria, pertussis and tetanus toxoids (DPT) vaccines was below 90\% in Latin American and middle-income countries and it is below $80 \%$ for low-income countries. ${ }^{[5]}$ An immunization campaign carried out by the World Health Organization (WHO) from 1967 to 1977 eradicated the natural occurrence of smallpox. When the program began, the disease threatened $60 \%$ of the world's population. Poliomyelitis is also going to be eradicated. Since the launch by WHO and its partners of the Global Polio Eradication Initiative in 1988, infections have fallen by $99 \%$, and five million people have escaped paralysis. Between 1999 and 2003, measles related deaths dropped worldwide by almost $40 \%$, and some countries have set a target goal to eliminate the disease. ${ }^{[6]}$

The Ethiopian health policy had given emphasis to the prevention and control of major communicable diseases. Thus, in Ethiopia expanded program on immunization (EPI) was initiated in 1980. The objective of the National Immunization Policy was to reduce mortality and morbidity in children from the EPI target diseases through the immunization of all children under the age of two in the first five year, but later after 1986 it was revised to focus children under one year of age in order to decrease the child exposure time to natural infection. The program had been planned to make immunization services available to $10 \%$ of the population in 1980 and to increase immunization access by $10 \%$ each year and reach to $100 \%$ coverage. ${ }^{[7]}$

Vaccination has been shown to be one of the most effective public health interventions in the world, through which a number of serious childhood diseases have been successfully eradicated. WHO recommends vaccination against a number of serious infectious diseases, including diphtheria, tetanus, pertussis, Hep B, invasive Hib disease, and measles for all children, and against pneumococcal disease, yellow fever, and rotavirus disease for children in some areas as part of their EPI. However, many infants and children still die every year from these diseases. ${ }^{[8]}$

It has been shown that in 2007 approximately 27 million infants in the world were not vaccinated against common childhood diseases, such as measles or tetanus. As a result, 2-3 million children are dying annually from easily preventable diseases, and many more fall ill. In the same year, 24 million children were not being reached with vaccines and over $10 \%$ of children under one year old in developing countries were not receiving even one dose of DTP vaccine. It has been also recognized that $16 \%$ of under five year mortality in Ethiopia is caused by lack of vaccine preventable diseases. ${ }^{[8]}$

According to the Ethiopian Demographic and Health Survey (EDHS) $2005,{ }^{[9]}$ only $20 \%$ of children $12-23$ months of age were fully vaccinated and $24 \%$ of children did not receive any vaccination. Accordingly, children are more likely to be vaccinated the first doses of vaccination. Vaccination of children in Ethiopia prevents different kind of child illness and deaths but the coverage is still low and many children do not receive even one dose of BCG. Objectives of the Study

- To determine the immunization coverage among children of aged 0-59 months old towards eight vaccine preventable diseases,

- To assess demographic and socio economic factors affecting immunization status among children aged 0-59 months and

- To assess the effect of media on immunization and vaccination status of children.

\section{Subjects and Methods}

The data for this study were obtained from the Central Statistical Agency (CSA) on the 2011 Ethiopian Demographic and Health Survey (EDHS). The 2011 EDHS was the third national demographic and health survey conducted by CSA. The 2011 EDHS was conducted with the primary objective of generating health and demographic information on infant health and children vaccination, family planning, adult and maternal mortality, child and maternal nutrition, malaria, women's empowerment, and knowledge of HIV/AIDS along with other household characteristics in the nine regions and two administrative regions both at rural and urban levels. The nationally representative EDHS 2011 data was collected under the guidance of the Central Statistical Agency of Ethiopia. Interviews were conducted with 16515 women, 14110 men. And a total of 11654 children (0-59 months) were included in the Ethiopia Demographic and Health Survey 2011 (EDHS 2011). The data was analyzed using the statistical package for social science (SPSS) version 20 and Stata version $11 .{ }^{[10]}$

\section{Variables Included in the Study}

The response or dependent variable in our case is the binary response variable which is called as "vaccination status of children". It can be identified as whether the child is vaccinated or not vaccinated.

Independent variable: variables considered in this study that influence vaccination status of children in Ethiopia are as shown in table 1 .

Table 1: Susceptible Independent variables and coding, EDHS, 2011.

\begin{tabular}{|l|l|l|}
\hline Variable & $\begin{array}{l}\text { Representation of } \\
\text { variables }\end{array}$ & Categories \\
\hline Place of residence & $\mathrm{X} 1$ & $\begin{array}{l}\text { 1=urban } \\
\text { 2=rural }\end{array}$ \\
\hline religion & $\mathrm{X} 2$ & 1=other \\
& & 2=Muslim \\
& & 3=protestant \\
& 4=orthodox \\
\hline Birth order & $\mathrm{X} 3$ & 1=first order \\
& & 2=second order \\
& & $3=$ third order \\
& & 4=forth order \\
& & 5=fifth order \& above \\
& & 1= Poor \\
& & 2=middle \\
& & $3=$ rich \\
\hline Wealth index & $\mathrm{X} 4$ & \\
& & \\
& &
\end{tabular}




\begin{tabular}{|c|c|c|}
\hline Region & $\mathrm{X} 5$ & $\begin{array}{l}\text { 1=Tigray } \\
2=\text { Afar } \\
3=\text { Amhara } \\
4=\text { Oromiya } \\
\text { 5=Somali } \\
6=\text { Ben-Gumuz } \\
7=\text { SNNP } \\
8=\text { Gambela } \\
9=\text { Hareri } \\
\text { 10=Addis Ababa } \\
\text { 11=Dire Dawa }\end{array}$ \\
\hline Sex of child & X6 & $\begin{array}{l}\text { 1.female } \\
\text { 2.male }\end{array}$ \\
\hline $\begin{array}{l}\text { mothers' level of } \\
\text { education }\end{array}$ & X7 & $\begin{array}{l}0=\text { secondary and higher } \\
1=\text { primary } \\
2=\text { no education }\end{array}$ \\
\hline $\begin{array}{l}\text { Frequency of } \\
\text { listening to radio }\end{array}$ & $\mathrm{X} 8$ & $\begin{array}{l}0=\text { not at all } \\
1=\text { less than once a weak } \\
2=\text { at least once a weak }\end{array}$ \\
\hline $\begin{array}{l}\text { Mothers' age in 5- } \\
\text { year groups }\end{array}$ & X9 & $\begin{array}{l}1=15-19 \\
2=20-24 \\
3=25-29 \\
4=30-34 \\
5=35-39 \\
6=40-45 \\
7=45-49\end{array}$ \\
\hline
\end{tabular}

The Logistic Regression Model: This study used logistic regression model which is the most important model for categorical response data, specially used for dichotomous variables i.e the outcome is either success or failure. The logistic regression model is a generalized linear model with random component. In a variety of regression applications, a response variable of interest has two possible qualitative outcomes, and therefore can be represented by a binary indicator variable taking on values 0 and 1 . We shall denote this response variable by $\mathrm{Y}$ and the two possible values are 0 and 1 or by the general terminology failure and success. Logistic regression allows one to predict a discrete outcome, such as group membership, from a set of predictor variables that may be continuous, discrete, dichotomous, or a mixture of any of these. ${ }^{[11]}$ Consider a collection of $\mathrm{P}$ independent variables which will be denoted by a vector $\mathrm{X}=(\mathrm{X} 1, \mathrm{X} 2 \ldots \mathrm{Xp})$. Let the conditional probability that the outcome of interest in a study is "vaccinated" be denoted by $\mathrm{P}(\mathrm{Y}=1 / \mathrm{X}=\mathrm{x})=\mathrm{P}(\mathrm{x})$. The ratio of the success $(\mathrm{Yi}=1)$ probability, $\mathrm{P}$ (xi) to that of $1-\mathrm{P}(\mathrm{xi})$ (failure $(\mathrm{Y}=0)$ probability) is given by:

$$
\frac{P\left(\mathrm{x}_{i}\right)}{1-P\left(\mathrm{x}_{\mathrm{i}}\right)}
$$

is known as the odds of success.

In terms of the odds, the logistic model can be written as:

$$
\frac{P\left(\mathrm{x}_{i}\right)}{1-P\left(\mathrm{x}_{\mathrm{i}}\right)}=\exp \left(\beta_{0}+\beta_{1} X_{i 1}+\beta_{2} X_{i 2}+\ldots+\beta_{p} X_{i p}\right),
$$

$\mathrm{i}=1,2 \ldots . \mathrm{n}$

Where $\exp (\beta \mathrm{o})$ the constant of the equation and $\exp (\beta \mathrm{j})$, $j=1,2, \ldots, p$ is the coefficients of the $j^{\text {th }}$ independent variable.

And the odds in favor of success for multivariable logistic regression will be
$\left(\frac{P\left(\mathrm{x}_{i}\right)}{1-P\left(\mathrm{x}_{\mathrm{i}}\right)}\right)=\exp \left(\beta_{0}+\beta_{1} X_{i 1}+\beta_{2} X_{i 2}+\ldots+\beta_{p} X_{i p}\right), \quad i=1,2, \ldots, n$

In which case, $P\left(\mathrm{x}_{i}\right)=\frac{e^{\beta_{0}+\beta_{1} X_{11}+\beta_{2} X_{12}+\ldots+\beta_{p} X_{i q}}}{1+e^{\beta_{0}+\beta_{1} X_{11}+\beta_{2} X_{12}+\ldots+\beta_{p} X_{i p}}}, i=1,2, \ldots, n$

Suppose we have a sample of $\mathrm{n}$ independent observations of (xi, yi) for $\mathrm{p}+1$ variables, where yi denotes the value of the dichotomous variable (in this case vaccinated or not vaccinated), and $x i$ is the value of the independent variables for the ith observation or individual. The general data layout can be represented as follows:

$$
X=\left(\begin{array}{ccccc}
1 & x_{11} & x_{12} & \ldots & x_{1 p} \\
1 & x_{21} & x_{22} & \ldots & x_{2 p} \\
\cdot & \cdot & \cdot & \ldots & \cdot \\
\cdot & \cdot & \cdot & \ldots & \cdot \\
\cdot & \cdot & \cdot & \ldots & \cdot \\
1 & x_{n 1} & x_{n 2} & \ldots & x_{n p}
\end{array}\right)_{n \times(p+1)} \quad \text { and } Y=\left(\begin{array}{c}
y_{1} \\
y_{2} \\
\cdot \\
\cdot \\
\cdot \\
y_{n}
\end{array}\right)_{n \times 1}
$$

Where, $\mathrm{X}$ is called the design or regression matrix. And without the loading column of 1's, this design matrix is said to be predictor data matrix. Thus, using the design matrix above, the conditional probability that the outcome of interest in a study "is vaccinated" (in this case, the child is vaccinated) can be written as:

$P\left(\mathrm{x}_{i}\right)=\frac{e^{\beta_{0}+\beta_{1} X_{1}+\beta_{2} X_{i 2}+\ldots+\beta_{p} X_{i p}}}{1+e^{\beta_{0}+\beta_{1} X_{11}+\beta_{2} X_{i 2}+\ldots+\beta_{p} X_{i p}}}=\frac{e^{X \beta}}{1+e^{X \beta}}=\frac{1}{1+e^{-X \beta}}$,

$\mathrm{i}=1,2 \ldots \mathrm{n}$

Where:

$\mathrm{P}(\mathrm{xi})$ is the probability that ith child is being vaccinated given that $\mathrm{p}$ predictor variables.

$\beta$ is a vector of unknown coefficients ( i.e $\beta=(\beta 0, \beta 1, \beta 2$, ...,Bp)t).

It is obvious that the response variable and the predictors do not have a linear relationship. However, to have a linear relationship we can use the logarism transformation. Thus, the transformation of the logistic regression is the logit transformation of $\mathrm{P}(\mathrm{xi})$, and it is given as:

$$
\begin{aligned}
& \log i t\left\{P\left(\mathrm{x}_{i}\right)\right\}=\log \left\{\frac{P\left(\mathrm{x}_{i}\right)}{1-P\left(\mathrm{x}_{\mathrm{i}}\right)}\right\}=\beta_{0}+\beta_{1} X_{i 1}+\beta_{2} X_{i 2}+\ldots+\beta_{p} X_{i p}, \\
& \mathrm{i}=1,2 \ldots, \mathrm{n}
\end{aligned}
$$

Maximum likelihood Estimation: Logistic regression is widely used to the model for outcomes of a categorical dependent variable. For a random variable $\mathrm{Y}$ assuming values either 0 or 1 , the probability $\mathrm{pi}(\mathrm{Y}=1)$ is given as:

$$
\begin{aligned}
& P(Y=1)=p=\frac{1}{1+e^{-x^{\prime} \beta}}, x^{t}=\left(1, x_{1}, x_{2}, \ldots, x_{p}\right), \\
& \log i t(p)=\log \left(\frac{p}{1-p}\right)=x^{t} \beta,
\end{aligned}
$$

Where $\beta$ is a vector of unknown coefficients, and $\mathrm{x}$ is a 
vector of independent variables. Since the values of the outcome variable are not available, it is not possible to estimate the parameters directly. Each observation can be considered as an outcome of a Bernoulli trial, and hence for the $\mathrm{i}^{\text {th }}$ observation:

$P\left(Y=y_{i}\right)=p^{y_{i}}(1-p)^{1-y_{i}}$, assuming the $\mathrm{n}$ observations are independent, the likelihood function is

$l(\beta)=\prod_{i=1}^{n} \mathrm{P}^{y_{i}}(1-\mathrm{P})^{1-y_{i}}=\prod_{i=1}^{n}\left(\frac{1}{1+e^{-x^{\prime} \beta}}\right)^{y_{i}}\left(\frac{e^{-x^{\prime} \beta}}{1+e^{-x^{\prime} \beta}}\right)^{1-y_{i}}$,

And the log likelihood function is given as:

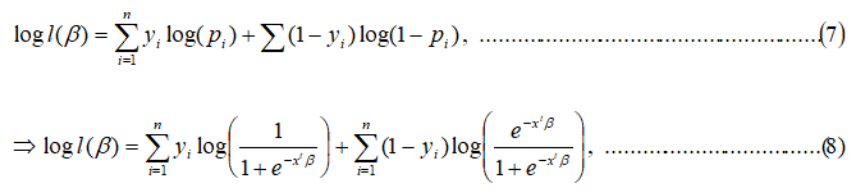

(15) can be written as:

$L(\beta)=\sum_{i=1}^{n} y_{i} \log \left(\frac{1}{1+e^{-x^{\prime} \beta}}\right)+\sum_{i=1}^{n}\left(1-y_{i}\right) \log \left(\frac{e^{-x^{\prime} \beta}}{1+e^{-x^{\prime} \beta}}\right), \quad$ where $\mathrm{L}(\beta)=\log \mathrm{l}(\beta)$

Hence by maximizing (15) above we can theoretically estimate the parameter $\beta$. To find an estimate of $\beta$ that maximizes $L(\beta)$, we differentiate $L(\beta)$ with respect to each component of $\beta$ and set the resulting $(p+1)$ equations to zero. Solutions are obtained by iterative algorithms that are programmed in available logistic regression packages like SPSS, and Stata,

Pseudo R2 for Logistic Regression: In logistic regression models, the descriptive measures of goodness-of-fit are based on likelihood ratios rather than raw residuals. There are several measures intended to mimic the R-squared analysis for the OLS regression model. The two different methods used to estimate the coefficient of determination in logistic regression case are: Cox and Snell and Nagelkerke. The Likelihood Ratio Test: The likelihood ratio test statistic (G2) is the test statistic commonly used for assessing the overall fit of the logistic regression model (the overall significance of all coefficients in the model). A "likelihood" is a probability, specifically the probability that the observed values of the dependent may be predicted from the observed values of the independents. Like any probability, the likelihood varies from 0 to 1 . Log likelihood is the basis for tests of a logistic model. Because -2LL has approximately a chi-square distribution, -2LL can be used for assessing the significance of logistic regression, analogous to the use of the sum of squared errors in OLS regression.

The -2LL statistic is the likelihood ratio. It is also called goodness of fit.

The likelihood-ratio test statistic is given by:

$$
G^{2}=-2 \log \left(\frac{l_{0}}{l_{1}}\right)=-2\left[\log \left(l_{0}\right)-\log \left(l_{1}\right)\right] .
$$

where, 10 is the likelihood of the null (current or simpler) model and 11 is the likelihood of the saturated model. The statistic $G$ plays the same role in logistic regression as the numerator of the partial F-test does in linear regression.

Under the global null hypothesis, $\mathrm{H} 0: \beta 1=\beta 2=\ldots=\beta p=0$ the statistic G2 follows a chi-square distribution. It is compared with a $\chi 2$ distribution with df the full model- df the null model.

Pearson's X2 Statistic: This approach is an alternative way of testing the hypothesis that the model fits the data by rely on the principle of comparing observed (yi) to predicted ( ) values and should be large if the model does not fit the data well. This statistic is defined as:

$$
X^{2}=\sum_{i=1}^{n}\left(\frac{\left(y_{i}-n_{i} \hat{p_{i}}\right)^{2}}{n_{i} \hat{p_{i}}\left(1-\hat{p_{i}}\right)}\right),
$$

Where $\mathrm{yi}=$ number of successes in the ith category, $\mathrm{ni}=$ number of individuals in the ithcategory, and pi = probability of success in the ith category. The distribution of X 2 is asymptotically Chi-square with $(n-p-1)$ degrees of freedom. Large values of X 2 can be taken as evidence that the model does not adequately fit the data.

Hosmer- Lemeshow Test: Hosmer-Lemeshow goodness-offit test divides subjects into deciles based on predicted probabilities and computes a chi-square from observed and expected frequencies. The test is similar to a $\chi 2$ goodness of fit test and has the advantage of partitioning the observations into groups of approximately equal size, and therefore there are less likely to be groups with very low observed and expected frequencies.

The Hosmer-Lemeshow test statistic is given by:

$$
H=\sum_{i=1}^{g}\left(\frac{\left(O_{i}-E_{i}\right)^{2}}{n_{i} \hat{p_{i}}\left(1-\hat{p_{i}}\right)}\right),
$$

Where Oi, Ei, ni, and pi denote the observed events, expected events, observations, and predicted risk for the $i^{\text {th }}$ risk deciles group. The test statistic asymptotically follows a $\chi 2$ distribution with g- 2 degrees of freedom. The number of risk groups may be adjusted depending on how many fitted risks are determined by the model. A no significant chisquare indicates a good fit to the data and, therefore, good overall model fit.

The Wald Statistic: The Wald test is a way of testing the significance of particular explanatory variables in a statistical model. In logistic regression we have a binary outcome variable and one or more explanatory variables. For each explanatory variable in the model there will be an associated parameter. The Wald test is one of a number of ways of testing whether the parameters associated with a group of explanatory variables are zero. ${ }^{[12,13]}$ If for a particular explanatory variable or group of explanatory variables different from zero, the Wald test is significant, then we would conclude that the parameters associated with these variables are not zero, so that the variables should be included in the model. In order to determine the worth of 
the individual regressor in logistic regression, the Wald statistic denoted as:

$$
W=Z^{2}=\frac{\hat{\beta}_{i}{ }^{2}}{\operatorname{var}\left(\hat{\beta}_{i}\right)}, \mathrm{i}=1,2, \ldots, \mathrm{p}
$$

Under the null hypothesis $\mathrm{H} 0: \beta \mathrm{i}=0(\mathrm{i}=1,2, \ldots, \mathrm{p})$, the statistic $\mathrm{W}$ is approximately distributed as chi-square with single (one) degree of freedom.

\section{Results}

The data to be analyzed for this study were obtained from Ethiopian demographic and health survey (EDHS) 2011 that consists the sample of under five year population. The initial population consisted of 11654 infants of age less than 59 months. Out of those children, 8058 (69\% of the total children in EDHS data) were selected and included in the study and others were excluded due to incompleteness and inconsistency of data on the variables which are considered as important for the analysis. Among all those 8058 sampled children in the study $71.2 \%$ are vaccinated and the rest $28.8 \%$ are not vaccinated. There is variation in vaccination coverage, ranging from only $40.3 \%$ of children fully vaccinated in the Affar region to $91.6 \%$ in Tigray region [see Table 3 below].

Table 2: Vaccination coverage of children in Ethiopia, EDHS, 2011.

\begin{tabular}{|l|l|l|l|l|}
\hline \multirow{2}{*}{$\begin{array}{l}\text { Receive } \\
\text { Vaccination }\end{array}$} & \multicolumn{4}{|c|}{ Types of Vaccination } \\
\cline { 2 - 5 } & BCG & DPT & POLIO & MEASLES \\
\hline Yes & $61.2 \%$ & $58.2 \%$ & $73.3 \%$ & $47.8 \%$ \\
\hline No & $38.8 \%$ & $41.8 \%$ & $26.7 \%$ & $52.2 \%$ \\
\hline
\end{tabular}

As it is shown in Table 2, the percentage of children age 059 months who have received the BCG vaccination was $61.2 \%$ and $58.2 \%$ had been vaccinated against DPT. The coverage for POLIO is relatively high $(73.3 \%)$. However, only $47.8 \%$ went on to receive the measles vaccine.

Table 3: Frequencies (percentage distribution) of Child's vaccination status within categories of explanatory variables, EDHS, 2011.

\begin{tabular}{|c|c|c|c|}
\hline & & \multicolumn{2}{|c|}{ Vaccination status of children } \\
\hline Variables & Categories & Not vaccinated & Vaccinated \\
\hline \multirow{7}{*}{$\begin{array}{l}\text { Mother's age } \\
\text { grouped }\end{array}$} & $15-19$ & $40.10 \%$ & $59.90 \%$ \\
\hline & $20-24$ & $30.40 \%$ & $69.60 \%$ \\
\hline & $25-29$ & $27.80 \%$ & $72.20 \%$ \\
\hline & $30-34$ & $28.90 \%$ & $71.10 \%$ \\
\hline & $35-39$ & $27.70 \%$ & $72.30 \%$ \\
\hline & $40-44$ & $25.50 \%$ & $74.50 \%$ \\
\hline & $45-49$ & $24.50 \%$ & $75.50 \%$ \\
\hline \multirow{2}{*}{$\begin{array}{ll}\text { Type } & \text { of } \\
\text { place } & \text { of } \\
\text { residence } & \\
\end{array}$} & Urban & $19.60 \%$ & $80.40 \%$ \\
\hline & Rural & $30.00 \%$ & $70.00 \%$ \\
\hline \multirow{3}{*}{$\begin{array}{l}\text { Mother's } \\
\text { educational } \\
\text { level }\end{array}$} & $\begin{array}{l}\text { Secondary } \\
\text { and higher }\end{array}$ & $12.60 \%$ & $87.40 \%$ \\
\hline & Primary & $18.90 \%$ & $81.10 \%$ \\
\hline & No education & $32.60 \%$ & $67.40 \%$ \\
\hline \multirow[t]{3}{*}{ Region } & Tigray & $8.40 \%$ & $91.60 \%$ \\
\hline & Affar & $59.70 \%$ & $40.30 \%$ \\
\hline & Amhara & $16.10 \%$ & $83.90 \%$ \\
\hline
\end{tabular}

\begin{tabular}{|c|c|c|c|}
\hline & Oromiya & $29.10 \%$ & $70.90 \%$ \\
\hline & Somali & $50.60 \%$ & $49.40 \%$ \\
\hline & B.Gumuz & $22.40 \%$ & $77.60 \%$ \\
\hline & SNNS & $22.90 \%$ & $77.10 \%$ \\
\hline & Gambela & $28.90 \%$ & $71.10 \%$ \\
\hline & Harari & $15.80 \%$ & $84.20 \%$ \\
\hline & Addis ababa & $15.60 \%$ & $84.40 \%$ \\
\hline & Dire dawa & $12.40 \%$ & $87.60 \%$ \\
\hline \multirow[t]{4}{*}{ Religion } & Other & $42.40 \%$ & $57.60 \%$ \\
\hline & Muslim & $27.10 \%$ & $72.90 \%$ \\
\hline & Protestant & $35.90 \%$ & $64.10 \%$ \\
\hline & Orthodox & $16.90 \%$ & $83.10 \%$ \\
\hline \multirow{3}{*}{$\begin{array}{l}\text { Frequency of } \\
\text { listening to } \\
\text { radio }\end{array}$} & Not at all & $32.40 \%$ & $67.60 \%$ \\
\hline & $\begin{array}{l}\text { Less than } \\
\text { once a week }\end{array}$ & $24.30 \%$ & $75.70 \%$ \\
\hline & $\begin{array}{l}\text { At least once } \\
\text { a week }\end{array}$ & $21.60 \%$ & $78.40 \%$ \\
\hline \multirow[t]{2}{*}{ Sex of child } & Male & $29.00 \%$ & $71.00 \%$ \\
\hline & Female & $28.60 \%$ & $71.40 \%$ \\
\hline \multirow{3}{*}{$\begin{array}{l}\text { Wealth } \\
\text { index }\end{array}$} & Poor & $35.10 \%$ & $64.90 \%$ \\
\hline & Middle & $25.20 \%$ & $74.80 \%$ \\
\hline & Rich & $19.10 \%$ & $80.90 \%$ \\
\hline \multirow{5}{*}{$\begin{array}{l}\text { Child birth } \\
\text { order }\end{array}$} & 1st order & $27.10 \%$ & $72.90 \%$ \\
\hline & 2nd order & $28.00 \%$ & $72.00 \%$ \\
\hline & 3rd order & $28.50 \%$ & $71.50 \%$ \\
\hline & 4 th order & $27.20 \%$ & $72.80 \%$ \\
\hline & $\begin{array}{ll}5 \text { th } & \text { and } \\
\text { above }\end{array}$ & $30.60 \%$ & $69.40 \%$ \\
\hline \multicolumn{2}{|l|}{ Total } & $28.80 \%$ & $71.20 \%$ \\
\hline
\end{tabular}

From [Table 3], we see that vaccination status of children varies for each mother's age group. The highest rate $(75.5 \%)$ of children vaccinated was observed for mothers in the age group 45-49. On the other hand the lowest rate $(59.8 \%)$ of vaccinated children was observed from mothers in the age group 15-19. Out of children who reside in urban areas $19.6 \%$ are not vaccinated, $80.4 \%$ are vaccinated. These figures are $30.0 \%$ and $70.0 \%$ for those children who reside in rural areas, respectively. The percentage distributions of child vaccination status differ by mother's education level. Accordingly, out of those children from non-educated mothers, $32.6 \%$ are not vaccinated, $67.4 \%$ are vaccinated. These figures are $18.9 \%$ and $81.4 \%$ for those children from mothers who have primary education level, respectively. For those mothers who have secondary and higher education level the percentages are $12.6 \%$ and $87.4 \%$, respectively.

Likewise, as Table 3 shows, vaccination status of children rate varied from one region to another. For instance, the lowest rate $(40.3 \%)$ of vaccinated children was observed for parents living in Afar region followed by Somali region $(49.4 \%)$. The highest rate $(91.6 \%)$ of vaccinated children was observed for parents in Tigray region followed by Diredawa $(87.6 \%)$.With regards to religion, $57.6 \%, 72.9 \%$, $64.1 \%, 83.1 \%$, of children were vaccinated from other, Muslim, Protestant, and Orthodox parents, respectively. The highest proportion $(42.4 \%)$ of not vaccinated children was observed for those parents with other religion followed by Protestant $(35.9 \%)$.

Table 3 also shows that the proportion of child vaccination status varies by parents' frequency of listening to radio. Accordingly, out of those children from parents of not at all listening to radio, $32.4 \%$ were not vaccinated. This figure is 
$24.3 \%$ for those children who are from parents listening radio less than once a week. For those parents who were listening radio at least once a week the percentage is $21.6 \%$. With regards to sex, $71.0 \%$ of male children are vaccinated and this figure is $71.4 \%$ for female children. Wealth index also contributes its own effect on vaccination status of children. The result indicates that $64.9 \%, 74.8 \%$, and $80.9 \%$, of vaccinated children were born from poor, middle, and rich families respectively.

\section{Multiple Binary Logistic Regression Analysis}

Here we considered two models: Model I contain all the 9 covariates while Model II excludes sex from the analysis.

The Hosmer-lemeshow test revealed that the p-value is 0.535 (>0.05) for model I and 0.633 (>0.05) for model II which is also insignificant. Therefore, both of our logistic regression models are good fit. AIC values for Model I and II are 8500.53 and 8498.538 , while the BIC values are 8724.351 and 8715.365, respectively. Since Model II has smaller values of both AIC and BIC, we conclude that it is a better fit to the data. The result of multiple binary logistic regression for Model II are shown in [Table 4] below.

\section{Evaluation of the final model}

The most common assessment of overall model fit in logistic regression is the likelihood ratio test, which is simply the chi-square difference between the null model (i.e., with the constant only) and the model containing the predictors. Under table 4 we can see that the -2 Log Likelihood statistics is 8436.538. This statistic measures how poorly the model predicts vaccination status of children, the smaller the statistic the better the model. SPSS does not give us this statistic for the model that had only the intercept; we know it to be 9673.985 (8436.538+ 1237.447). Adding the predictors reduced the -2 Log Likelihood statistic by $9673.985-8436.538=1237.477$, which is the $\mathrm{X} 2$ statistic for omnibus test. The two pseudo $\mathrm{R}$ square measures namely, Cox and Snell and Nagelkerke are .142 and .204 respectively for the final model (Model II), which are good enough.

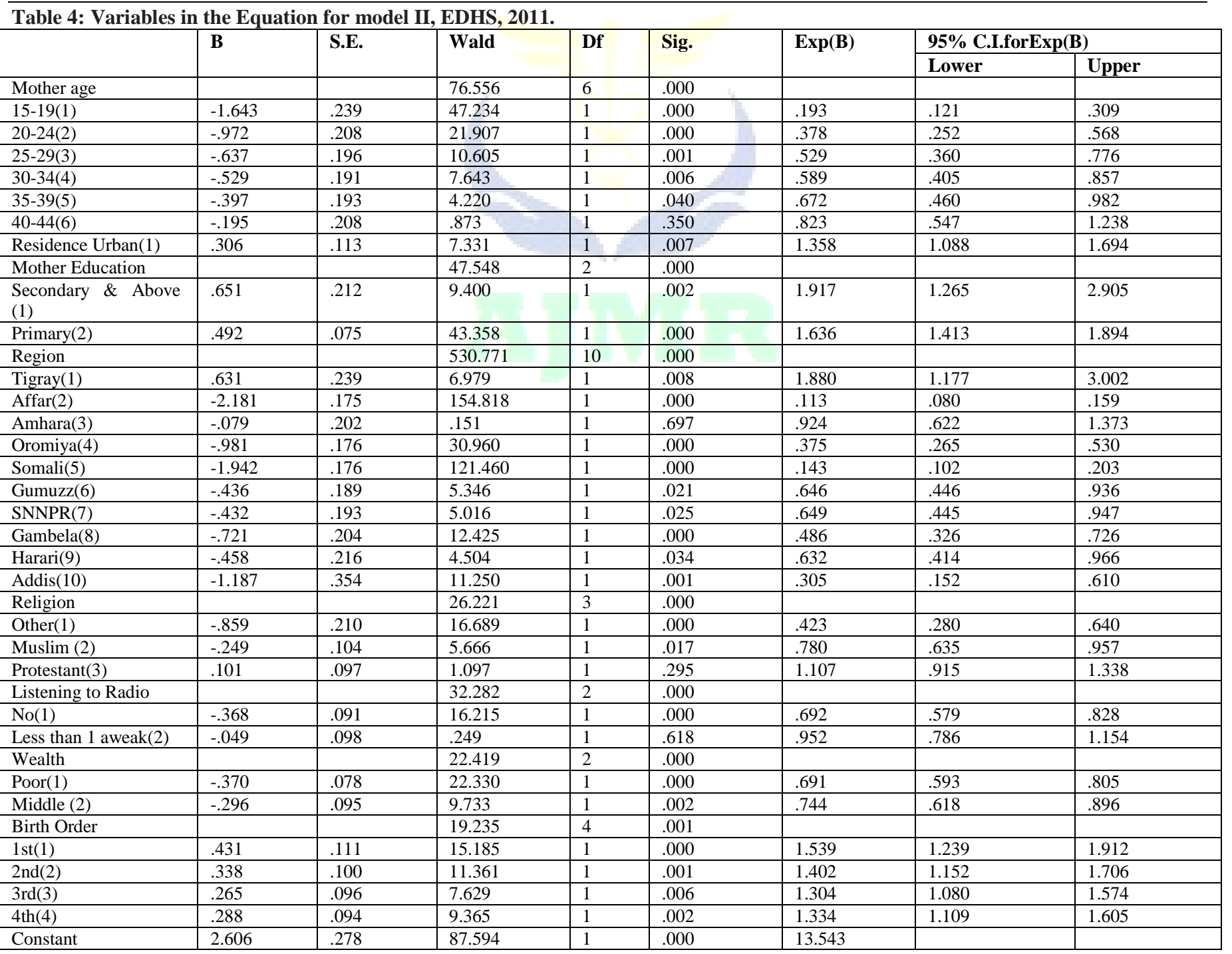




\section{Discussion}

Even though the Ethiopia expanded program on immunization (EPI) was started with an intention of reaching $100 \%$ to the vaccination coverage of children, the coverage is still low. In this study only $71.2 \%$ of the Ethiopian children get vaccination to prevent eight vaccine preventable disease and $28.8 \%$ are did not receive any kind of vaccination. This coverage is high as compared to 2005 EDHS report which states that, only $20 \%$ of children were fully vaccinated. The coverage is high in Tigray region, older mothers, listening to radio, first birth older children, urban mothers, literate mothers and rich parents. It is low in Affar and Somali region, younger mothers, in those who listen radio, higher birth order children, rural mothers, illiterate mothers and poor parents. Other study reports that, the odd of having full immunization was twice higher among children from parents with college education compared to those with no education. ${ }^{[14]}$ However, the odds of complete immunization status among children from parents with secondary education were slightly higher than those with no education and children from mothers aged 4549 years old had the highest vaccination coverage compared to mothers of other age groups. Children from the middle level class have 1.2 odds of having complete vaccination status for their children as compared to those that are poor. (OR: $1.285,95 \%$ CI: $1.173-1.408, \mathrm{p}<0.001$ ). The result is also consists with previous study which reports that, regional differences in vaccine coverage vary from $10 \%$ in the state of Somali to over $80 \%$ in the state of Tigray and Vaccination coverage of children was significantly higher in urban areas than rural areas. ${ }^{[15]}$

We can interpret the odds ratio of age group obtained in [Table 4] using the reference category mother's age group 45-49. The odds of children being vaccinated has decreased by a factor of 0.193 for mothers in the age group 15-19 compared to those in the age group 45-49 controlling for other variables in the model. Similarly, the odds of children being vaccinated decreased by a factor of 0.378 for mothers in the age group 20-24 compared to those in the age group 45-49 controlling other variables in the model. As we have seen in the table the odds ratio for mothers' age group from 25-29, 30-34, 35-39, and 40-45 are 0.529, 0.589, 0.672, and 0.823 respectively, which indicates that older mothers are more likely to vaccinate their children as compared to those who are younger. The result is consistent with the previous study that reports children from mothers aged 45-49 years old had the highest vaccination coverage compared to mothers of other age groups. ${ }^{[14]}$ But according to earlier study children of middle age mothers are more likely to be fully immunized than children of youngest and oldest mothers. ${ }^{[16]}$

For the variable place of residence, the reference category is rural, mothers living in urban area are $35.8 \%$ more likely to vaccinate their children as compared to those living in the rural area controlling for other variables in the model. This may be because of greater access to modern facilities and medical care as well as other social amenities in urban areas. The study contradicts with previous study which report that fully vaccinated coverage was higher in rural than in urban areas, $(80 \%)$ vs. $(67.5 \%) .{ }^{[17]}$ Other study which reports that, vaccination coverage of children was significantly higher in urban areas than rural areas. ${ }^{[15]}$ The result is also consistent with earlier study, being from a rural area was significantly associated with not being fully vaccinated. ${ }^{[18]}$

In this study, mother's education was an important predictive factor for vaccination status of children, the reference category is no education, the odds of having vaccinated children is increased by a factor of 1.917 for mothers with primary education compared to those with no education controlling other variables in the model. Mothers with secondary and higher level of education are $63.6 \%$ more likely to vaccinate their child as compared to those with no education level controlling other variables in the model. This indicates that educated mothers are more likely to vaccinate their children because of educated partners have better health and nutrition knowledge and child rearing practices than uneducated ones which both contribute to improved child health. In the literature, there is strong consistency in the relationship between mother's education and vaccination status of children. Mother education was found to be a strong determinant factor for child vaccination. The odds of having full immunization was twice higher among children from parents with college education compared to those with no education (OR: 2.116, CI: $1.109-4.036 \mathrm{p}=0.023)$. However, the odds of complete immunization status among children from parents with secondary education were slightly higher than those with no education. ${ }^{[14]}$ The study result also consistent with other study that reports educated mothers were more likely to have their children immunized than mothers who had no education. Mothers with secondary and higher education had a 2.4 times higher chance for full immunization. ${ }^{[19]}$ Similarly a study done by the previous time found that mothers who had primary, secondary and higher education were more likely to fully immunize their children than those with no education. ${ }^{[16-18]}$

For the fourth variable, region, taking the reference category Dire Dawa, the odds of children being vaccinated has increased by $88 \%$ among children living in Tigray compared to those in Dire Dawa controlling for other variables in the model. Similarly, the odds of being vaccinated decreased by a factor of 0.113 for children living in Afar compared to Dire Dawa controlling for other variables in the model. Children living in Somali region are $14 \%$ less likely to be vaccinated as compared to those living in Dire Dawa controlling other variables in the model. The odds of being vaccinated decreased by a factor of 0.646 , $0.305,0.649$, and 0.632 for children living in B.Gumuz, Addis Ababa, SNN, and Harari respectively compared to Dire Dawa controlling for other variables in the model. This study showed that there is an observed regional discrepancy with respect to vaccination status of children. As compared to the reference region namely, Dire Dawa children in Gambela, Oromiya, Somali and Affar regions are less likely 
to be vaccinated. On the other hand children who live in Tigray region are more likely to be vaccinated than those in Dire Dawa. The result is consistent with other study, a child from the Somali region was only 0.005 times $(95 \% \mathrm{CI}$ [0.002-0.016] as likely to be fully vaccinated as a child from Addis Abeba. ${ }^{[18]}$

In our study, the religious affiliation of the parent was found to be significantly associated with children vaccination status, the reference category was Orthodox and the odds of children being vaccinated is 0.423 times lower for Other religion compared to Orthodox controlling for other variables in the model. And for the second category the odds of children being vaccinated is 0.78 times lower for Muslim compared to Orthodox controlling for other variables in the model. According to our findings, the highest proportion of vaccination is performed among Orthodox religion. It could be that religion has an immense social, economic, and political significance in most societies, and thus plays an important role in sanctioning or promoting acceptance of or creating resistance to vaccination. Similar studies have also shown that children from Muslim parents have 0.3 (95\% CI: $0.183-0.731$, $\mathrm{p}=0.004$ ) odds of having complete vaccination status for their children as compared to children from Christian homes. ${ }^{[14]}$ But according to previous study Muslim religion $(\mathrm{OR}=4.3)$, increased the risk of nonimmunization significantly. ${ }^{[20]}$

In [Table 4] we can also interpret that poor parents are $69 \%$ less likely to vaccinate their child as compared to the rich one controlling other variables in the model. The odds of children being vaccinated has decreased by a factor of 0.744 for middle income parents compared to rich parents controlling for other variables in the model. According to the findings of this study, mothers with low household economic status (poor mothers) are less likely to vaccinate their children as compared to those who are rich in household economic status. This indicates that the vaccination status of children increases as wealth index increases. The finding is consistent with earlier study, study hypothesized that a significant inclination was observed in middle class families to get their children fully immunized as compared to the lower class. ${ }^{[19]}$ Other study report that children from the middle level class have 1.2 odds of having complete vaccination status for their children as compared to those that are poor is also consistent with our study. ${ }^{[14]} \mathrm{A}$ study in India also found that low socioeconomic status $(\mathrm{OR}=10.8)$, increased the risk of non immunization children significantly. ${ }^{[20]}$ This finding is consistent with the results of the previous study that monthly income as the only factor associated with defaulting from immunization. ${ }^{[21]}$

For the variable frequency of listening radio, the reference category is at least once a week, the odds of children being vaccinated is $69.2 \%$ lower for parents that are not at all listening to the radio compared to those listening at least once a week controlling for other variables in the model. The result confirmed that mothers who had no access to uses of vaccination lessons through radio are less likely to vaccinate their child as compared to those who did have access.

Lastly [Table 4] shows us first order children are $53.9 \%$ more likely to be vaccinated as compared to those who are five and above order children controlling other variables in the model. The odds of the second order children being vaccinated has increased by a factor of 1.402 as compared to those who are five and above order controlling other variables in the model. Similarly, the odds of children being vaccinated have increased by a factor of 1.304 for third order children as compared to those who are five and above order controlling other variables in the model. Lastly fourth order children are $33.4 \%$ more likely to be vaccinated as compared to those who are five and above order children controlling other variables in the model. In the finding we obtain that vaccination status of children was shown to decrease with increase in birth order. This finding is consistent with the results of other study, higher birth order $(\mathrm{OR}=4.3)$ increased the risk of non immunization significantly. ${ }^{[20]}$

\section{Conclusion}

Despite the progress that has been made in the country to improve child health by immunizing eight vaccine preventable diseases - tuberculosis, diphtheria, tetanus (including neonatal tetanus through immunization of mothers), pertussis, polio, measles, hepatitis B (HepB), and homophiles influenza (Hib), child illness and mortality remain high in Ethiopia. The study was intended to identify the factors that affect vaccination status of under five year children in Ethiopia based on EDHS 2011 data. Nine covariates were selected for the study and 8 uni-variable binary logistic regression models were developed to assess the relationship between child vaccination status and the selected variables.

The study revealed that socio-economic and demographic variables have significant effect on the vaccination status of children in Ethiopia. The results of the log odds model show that mothers' age in 5-year groups, type of residence, mothers' education level, region, religion, frequency of listening to radio, wealth index and birth order are the most important factors of child vaccination status in Ethiopia.

Specifically the study revealed that higher vaccination status of children is more likely for children from educated mothers as compared to those from non-educated mothers. Considering birth order, high birth order is negatively associated with vaccination status of children. Children from urban parents also have more chance to be vaccinated than those from rural partners. Moreover, children from Gambela, Oromiya, Somali and Affar regions are less likely to be vaccinated as compared to Dire Dawa. Frequency of listening to radio is positively associated with vaccination status of children. The result also indicated that child from poor mothers is less likely to get vaccination as compared to rich mothers.

The health offices should work properly to raise the awareness of parents for vaccination by designing proper health education. Improve parents' access to education in all 
areas to enhance the quality of care and attention they can provide to their children. Programs like expanded program on immunization (EPI) should be extended all districts of Ethiopia. Policies and plans have to be put in place to vaccinate all children in Ethiopia.

\section{Ethics, consent and permissions}

We have used the EDHS data collected on 2011. Ethical clearance for the survey (EDHS 2011) was provided by the EHNRI (Ethiopian Health and Nutrition Research Institute) Review Board, the National Research Ethics Review Committee (NRERC) at the Ministry of Science and Technology, the Institutional Review Board of ICF International, and the CDC (Centers for Disease Control and Prevention). The respondents were informed about the purpose of the survey verbally and their consent to participate was asked obtained. Voluntary participation in the survey was assured while interviewing participants. [10] The analyses of this paper are confined to secondary data. Approval to analyze is requested from the CSA [Ethiopia] and we have been authorized to download data from the DHS online archive. After downloading, authors of this study have maintained the confidentiality of the data.

\section{$\underline{\text { Abbreviations }}$}

$\begin{array}{ll}\text { AIC } & \text { Aqaki Information Criteria } \\ \text { BIC } & \text { Baysian Information Criteria } \\ \text { BCG } & \text { Bacillus Calmette-Guérin } \\ \text { CDC } & \text { Centers for Disease Control and Prevention } \\ \text { CSA } & \text { Central Statistical Agency } \\ \text { DHS } & \text { Demographic Health Survey } \\ \text { DPT } & \text { Diphtheria, Tetanus, and Pertussis } \\ \text { EDHS } & \text { Ethiopian Demographic and Health Survey } \\ \text { EHNRI } & \text { Ethiopian Health and Nutrition Research Institute } \\ \text { NRERC } & \text { National Research Ethics Review Committee } \\ \text { SNN } & \text { Southern Nation and Nationalities } \\ \text { WHO } & \text { World Health Organization }\end{array}$

\section{Acknowledgements}

The authors of this article would like to thank Central Statistical Agency (CSA) of Ethiopia for availing the data used in this study. We also would like to extend our appreciation to Mr. Gashu Ebrahim Dawud for editing the manuscript.

\section{Authorship Contributions}

Idea/Concept: Gedif Mulat, Kasim Mohammed Yesuf, Jibril Seid Yesuf; Literature Review: Gedif Mulat, Kasim Mohammed Yesuf, Jibril Seid Yesuf; Design and Method Selection: Gedif Mulat, Kasim Mohammed Yesuf, Jibril Seid Yesuf; Data Analysis and/or Interpretation: Gedif Mulat, Kasim Mohammed Yesuf; Writing the Article: Gedif Mulat, Kasim Mohammed Yesuf, Jibril Seid Yesuf; References and Finding part writing and making corrections: Gedif Mulat, Kasim Mohammed Yesuf, Jibril Seid Yesuf; Critical Review: Gedif Mulat, Kasim Mohammed Yesuf, Jibril Seid Yesuf. All authors read and approved the final manuscript.

\section{References}

1. WHO. (2012). Vaccines. Cited by, http://www.who.int/topics/vaccines/en/. Accessed on August 12, 2013

2. Arevshatian, L., Clements, C. J., Lwanga, S. K., Misore, A. O., Ndumbe, P., Seward, J. F. (2007).An Evaluation of Infant Immunization in Africa. A transformation in Progress. Bulletin of the World Health Organization, 85:449-457.

3. Niederhauser, V. and Markowitz, M. (2007). Barriers to Immunizations: Multiethnic parents of under- and un-immunized Children speak. Journal of the American Academy of Nurse Practitioners. 19(1): 15-23.

4. UNICEF. (2005).Immunization Remains Vital to Child Survival, New York

5. World Bank. (2003). World Development Report 2003: Investing in Health. New York: Oxford University Pres.

6. WHO.(2005). Immunization against Diseases of Public Health Importance. Geneva, cited 2010 September 13.

7. Berhane, Y., and Yigzaw, A. (2006).Vaccine Preventable Disease and Immunization Program inEthiopia. Addis Ababa: Shama Books: 35468 .

8. WHO. (2009). Global Elimination of Measles. Geneva, World Health Organization.

9. CSA [Ethiopia] and ORC Macro (2006). Ethiopia Demographic and Health Survey 2005: Addis Ababa, Ethiopia, and Calverton, Maryland, USA: Central Statistical Agency and ORC Macro.

10. CSA [Ethiopia] and ICF International: Ethiopia Demographic and Health Survey 2011. Addis Ababa Ethiopia and Calverton, Maryland, USA: Central statistical Agency and ICF International; 2012.

11. Gellman A \& Hill J (2007). Data Analysis Using Regression and Multilevel/Hierarchical Models. Cambridge, UK, Cambridge University Press.

12. Agresti, A. (1996).An Introduction to Categorical Data Analysis. John Wiley and Sons, In New York.

13. Polit, D. (1996). Data Analysis and Statistics for Nursing Research. Appleton \& Lange, Stamford, Connecticut.

14. Lucius, D. (2013). An Examination of Mothers' Socio-Demographic Factors Associated with Incomplete Vaccination Status among Underfive Populations in Malawi. Institute of Public Health, 285.

15. Yigzaw, A., Kidane, T., Sahilemariam, Y., Bulto, T., Mengistu, H., Belay, T.(2006). National EPI Coverage Survey, Ethiopian Journal of Health Development. 22(2):148-57.

16. Mosiur, R., and Sarker, O-N.(2009). Factors Affecting Acceptance of Complete Immunization coverage of Children under five years in Rural Bangladesh. Salud Publica Mex.52 (2):134-40.

17. Kidane, T. and Tekei, M. (2003).Factors Influencing Child Immunization Coverage in Rural District of Ethiopia. Ethiopian Journal of Health Development. 17(2):105-10.

18. Sharmily, R. (2009).Risk Factors for Childhood Immunization Incompletion in Ethiopia. Public Health thesis, Paper 90.

19. Biswas, S., Abu, D. and Fasiul, A. (2001).Factors Affecting Childhood Immunization. The Pakistan Development Review.40 (1): 57-70.

20. Bhola, N., Singh, J., Shally, A., Vidya, B., Vishwajeet, K., Singh, S.K. (2007). Determinants of Immunization Coverage among 12-23 Months old Children in Urban slums of Lucknow distric. India. 61 (11):598-606.

21. Tadesse, H., Deribew, A. and Woldie M. (2009). Predictors of Defaulting from Completion of Child Immunization in South Ethiopia, A case control study. BMC Public Health.9:150-155. 
Copyright: () the author(s), 2019. It is an open-access article distributed under the terms of the Creative Commons Attribution License (CC BY 4.0), which permits authors to retain ownership of the copyright for their content, and allow anyone to download, reuse, reprint, modify, distribute and/or copy the content as long as the original authors and source are cited.

How to cite this article: Alemayehu GM, Yesuf KM, Yesuf JS. Factors Affecting Immunization Status of Children Aged From 0-59 Months in Ethiopia. Asian J. Med. Res. 2019;8(1):CM01-CM10.

DOI: dx.doi.org/10.21276/ajmr.2019.8.1.CM1

Source of Support: Nil, Conflict of Interest: None declared. 